\title{
Group Leadership for Effective Contact Sessions Within the Distance Education Setting
}

\author{
Sharon Thabo Mampane \\ University of Pretoria, Groenkloof Campus, Pretoia, Gauteng Province, South Africa 0002 \\ Telephone: +27124202499, Fax: +27124203581, E-mail: sharon.mampane@up.ac.za
}

KEYWORDS Leadership. Part Time Lecturers. Student Interaction. Facilitation Skills. Improved Practices. Student Support

\begin{abstract}
The use of regular contact sessions, where groups of facilitators present lessons under professional guidance of a leader, has emerged as a popular mode of delivering education to distance education students in South Africa in recent years. To date, not much has been written about the role that facilitation group leaders play during such contact sessions in distance education institutions. Drawn from external service providers such as educators and other experts in education, facilitation group leaders are selected and appointed on the basis of their prior experience in teacher education as well as their current understanding of leading teams of facilitators during contact sessions. Their role as team leaders is critical for a successful organisation and effective education service delivery through the contact session model. This study sought to examine the role of facilitation group leaders in the distance education contact sessions. In this study, the researcher followed a qualitative research approach to collect data through interviews with purposely selected leaders of facilitation groups in two South African provinces. The results indicate that a positive relationship prevailed among the team members which was ascribed to experience, competency and commitment. Recommendations were that group leadership be done on a rotational basis since excellent leadership of facilitators depended on all facilitators' competency and skills which minimised the work of the group leader. These findings may inform organisations using group leader components at DE contact sessions about strategies to use when assigning facilitators to group leadership.
\end{abstract}

\section{INTRODUCTION}

This paper examines the leadership roles of the distance education facilitator group leader (FGL) for effective contact sessions within the Distance Education (DE) programme. Distance education provides an opportunity to those students who are unable, or cannot participate in campus-based and fixed time study and therefore requires DE leaders guidance through mechanisms that steer and create an enabling environment for student learning (Ogina and Mampane 2013). In South Africa, DE is provided by facilitators at public universities and universities of technology at contact sessions where students engage with learning materials and the facilitator (Matsilisa 2007: 1; Ogina and Mampane 2013). There is a demand and need for value and quality in educational distance learning programmes in colleges and universities as well as an increased demand for more talented facilitators for learner success (Department of Higher Education and Training 2014). The purpose of this study is to ensure that the leadership roles of FGLs result in effective delivery of the DE programme through information communication, interpersonal relationships, and managerial roles and activities. FGL activities also in- clude displaying exemplary leadership skills such as outlining of team goals and encouraging and motivating team members to deliver a valuable and quality teaching and learning programme that displays distinct competencies for lasting competitive advantage.

The DE factors that contribute to success or failure of a DE programme include the extent to which all facilitators have been trained, prepared and supported before the contact sessions, as well as the facilitators' ability to interact with team members and students at DE contact sessions (Mampane and Ogina 2012). The presence of effective distance education group leadership in DE could well make the difference between success and failure. FGLs are a new intervention for a group of facilitators to be led by a selected facilitator leader at contact sessions. This type of leadership differs from other types of leadership in education in that it creates a collegial and supportive environment at contact sessions. With appropriate training, the level of understanding and experience of the FGL is enhanced and FGLs become highly competent and deliver quality leadership. If the facilitator is not adequately trained, abilities may be curtailed and interaction with team members may be difficult (Abrami et al. 2011). It is, however, not apparent 
as to what criteria is used to appoint FGLs, but, the new facilitator role however requires of the group leader to be more receptive and adaptive to opportunities for improving the success of DE to can endorse, articulate and facilitate distance education goals crafted by the institution.

\section{Leading DE Facilitation}

The concepts leadership and management, in South Africa, though different, are used interchangeably in the context of schools and organisations (Bush 2008). Leaders influence the attainment of goals while managers attain goals through structures and processes put in place in the organisation. Leadership requires competency to influence and should result in the achievement of goals entrenched in the vision and values of the organisation, or else mediocrity or failure may result (Yeager and Nafukho 2012). Good leadership and management is essential for the functioning of organisations (Bush 2010), thus the selection and appointment of leaders in Distance Education should be done according to correct implementation of principles, criteria and procedures (Mampane 2015). Before contact sessions, group leaders contact the venue coordinator days in advance for a meeting to get information about the venue logistics. The group leader, along with all the presenters visit the contact session venue to ensure that the necessary signage and student guidance is clear and that all plugs, projectors, lights, and other relevant teaching materials are in working condition prior to the facilitation of contact sessions (Abrami et al. 2011: 86).

The reality in appointing DE group leaders, however, does not always match facilitator expectations or promote group advancements (Bush 2010). This often results in dissatisfactions and tension (Glenn 2009). The University is responsible for the selection, and appointment of leaders for DE management on behalf of the Unit for Distance Education. Thus, candidates who qualify and satisfy the criteria are considered for appointment (Mampane 2009) because appointing a competent person may help improve the way the institution operates (Northouse 2010) to attain DE goals. Bush (2010), however, argues that appointments in an institution cannot simply be taken as proof of competence but that issues such as history, culture and community should be considered.

\section{Group Leadership at Contact Sessions}

DE leader should possess experience and internalised understanding of their own capacity to lead. Institutions practising DE should be more open and adaptive to opportunities for improving the success of DE. Leadership in DE is a crucial factor for education effectiveness and organisational success and improvement and thus Distance education are marketed as cost-effective ways to rescue struggling educational institutions in developing countries, particularly in sub-Saharan Africa (SSA) (Muhirwa 2009). Higher Education Institutions continuously market their programmes to attract an increasingly large number of in-service teachers to attend traditional face-to-face contact sessions during school holidays (Muhirwa 2009). As this dynamic becomes more frequent and more prevalent, institutions have to be more receptive and adaptive to opportunities for playing exciting new roles in the education arena (Copeland 2010).

FGLs leading teams at DE contact sessions require a set of attitudes and behaviours that create conditions for improved success in the delivery of DE to adults (Knowles 1980) because DE has changed from mere facilitation and dissemination of information to team work under a group leader (Yeager and Nafukho 2012).With regard to DE at the University of Pretoria (UP), it is important to note that effective group leadership is mainly confined to administrative roles since module coordinators are influential experts of the content of their modules. The question posed is: How do group leaders at contact sessions ensure contact sessions are delivered effectively? Research and writing in this emerging field has not given consideration to this dimension of team leadership at contact sessions and its influence on the success and delivery of DE contact sessions. The introduction of FGLs at UP recognises and encourages the importance of DE success and improvement and the way facilitators and students should interact.

A significant amount of research has been done into the benefits of collaborative learning in face-to-face learning environments conducted by facilitators at contact sessions (Copeland 2010; Gallen and Oomen-Early 2008; Johnson and Johnson 2004), but, there are a few studies investigating the role of group leaders in a DE contact session for collaborative team work. With 
the increase of DE programmes, changes are necessary in the design of instruction and support for the effective functioning and delivery of the DE programmes.

\section{The Role of a Facilitation Group Leader (FGL)}

Having a trained team leader at the Distance Education contact session encourages collaborative team work and may lead to improved socialization skills and enhanced critical thinking (Barkley 2010; Jegede 2002). Other benefits of collaboration include reflection, peer feedback and the reduction of facilitator anxieties in DE settings (Barkley 2010; Vos et al. 2011). Teams in DE are involved in two types of interaction: interaction with content and interaction with other people. The FGL is a member of a team and is subsequently in charge of leading the team though not in total control of the learning environment. Members depend on each other to achieve the learning outcomes for the DE courses (Barkley 2010; Smith 2005).

One factor that affects the FGLs' role in DE is the transactional distance gap. Transactional distance is the gap of understanding and communication between the facilitators and the FGL caused by geographic distance. The FGL encourages interpersonal interaction of all facilitators at DE contact sessions from geographically separated areas. The most important role of the FGL is to accept the responsibility of keeping the group united and to maintain group harmony (Copeland 2010). The FGL must be able to bridge the gap through skilful leadership techniques, distinctive leadership roles and the facilitation of interaction (Copeland 2010).

\section{Meeting the Needs of the Manager and Other Facilitators}

Numerous studies have shown that having a positive group leader usually results in higher achievement of institutional goals and better psychological connections between group members and improved self-esteem (Yeager and Nafukho 2012; Vos et al. 2011). Having a positive group leader usually results in the achievement of institutional goals and the completion of collaborative tasks at DE. The FGL should constantly communicate with the group to clarify their roles and group tasks. A group leader delegates tasks to team members and encourag- es team support. Johnson and Johnson (2004) specify five basic elements needed for effective group collaboration: (a) positive interdependence, (b) promotive/supportive interaction, (c) individual accountability, (d) appropriate use of social skills, and (e) group handling. Supportive interaction encourages group members to trust the group leader and to act as trustworthy members themselves.

\section{Getting The Best From Individuals}

FGLs who foster positive interdependence between themselves and the team members commit team members to the achievement of institutional goals. Each member in a group can only succeed if the group achieves. Where there is trust, the group feels free to acknowledge and challenge each other's ideas, thus, facilitating each other's efforts. Trust in a leader also ensures each member's active participation in group tasks and individual accountability is taken into account (Mampane 2012). Facilitator group leaders (FGLs) who establish cordial group cohesion among facilitators at DE Contact Sessions (CS) also ensure that basic requirements for DE module delivery are met. Clear communication and constructive conflict resolution in a leader facilitates collaborative learning for improved social skills such as social interaction, reciprocal interaction and effective collaboration (Van Emmerik et al. 2011; Barkley 2010).

Group leadership centres on communicating information through technologies and communication systems available in the institution such as short message systems (sms), e-mail, cell phone and telephone calls to support the delivery of DE programmes at contact sessions. FGLs guide, monitor and develop all members' at DE to ensure time is used appropriately for improved quality education of DE learners. Cooperation among team members guarantee trust and respect through the skills and experience of a FGL. A group leader who respects each individual contribution of the group members can handle group dynamics (Vos et al. 2011; Yeager and Nafukho 2012). Such a FGL who has the ability to lead diverse people will also strengthen group skills which according to Mampane (2012) require incorporating well-planned collaborative activities into DE to benefit both the FGL and the facilitators. 


\section{Facilitator Administration}

Before travelling to the contact session venues, the FGL communicates telephonically or via sms to the facilitator team members about his/ her contact details, the venue they are travelling to, the travel times and the meeting place and time. After all facilitators are informed, the group then travel together to the contact session through hired cars or by plane. On arrival at the contact session venue, the FGL holds a meeting with the facilitators to guide them about the activities of the week. The meeting starts with introductions of group members from different areas. Facilitators then work together with the FGL in organising the venue logistics. All members travel to the venue the day before to put up signs that will guide students to the modules and classes they have to attend. The venue classrooms are checked for all the necessary resources for facilitation, such as, overhead projectors, data projectors and the availability of electricity at the venues. In the event of electricity being gone during facilitation, charts, marking pens and prestik/bostik adhesive are used as back up resources. The class time table and module time table, evaluation list, registration forms for class attendance and for exam writing are managed by facilitators who work as a team with the facilitator group leader. Information about the number of students who attended the contact session, new students at the venue, and registrations for the examination is recorded by the different facilitators and given to the FGL to report to the Unit of Distance Education at the said institution. Administration queries are given to the Administration personnel travelling with the team by the FGL (University of Pretoria 2012).

\section{Conceptual Framework}

The conceptual framework of this study is lodged in legislation/governance. The focus is on policy, regarding the selection and appointment of personnel and implications for organisational governance. More specifically, appointment policy aims at determining the quality of procedures and processes for selection and appointments in organisations (Marmor 2005). The process of appointing FGLs should provide an appropriate balance between all contesting candidates. Thus the principles, equity and diversity require that the interests of persons, who are part of the society, even if different from each other, be compared and weighed (Marmor 2005). Equity and representivity, however, are often not easy to achieve because individuals are usually cognitively biased towards their interests and as a consequence, controversy over the principle of equity and diversity often reflects such conflicts (Mampane 2009). Failure to consider the common good of a particular person may therefore imply that the person concerned ignores his/her own distinct interests (Marmor 2005).

Informing this purpose is the assumption that if the procedures followed are genuinely democratic, the outcomes would not only be justifiable but also just because authority would be grounded in the decision-maker/s (Naidoo 2004). According to Saunders (2011), current appointment policies do not necessarily enhance greater participation and, may in fact, contradict moves towards equitable practices. If appointment policies disregard individual rights in democracy, conflict may arise over competency in leadership and management.

\section{RESEARCH METHODOLOGY}

A qualitative research design within the interpretive paradigm was used. Ten purposely selected participants (eight facilitators and two group leaders) volunteered to be interviewed in this study. The participants came from each of the two provinces, Gauteng and Limpopo, during the long contact sessions for the Bachelor of Education Honors degree (Education Management) programme. Data was collected through semi-structured interviews to identify research gaps in skills and competences necessary for leading groups of facilitators at DE. Participants ranged in age from 40 to 65 years in age because the policy of the University is that facilitators should not be over the age of 65 years. The main question asked was: How are distance education group leaders selected for leading facilitators at contact sessions? The sub questions were: What are the expectations of selected FGLs of DECS? What are the experiences of leading facilitators at a DECS? How are FGLs supported by facilitators at the DECS? How is teamwork ensured at the DECS? and What are your opinions about the leadership and management of DECS?

\section{Data Collection}

The researcher invited the facilitators for an interview of about 45 minutes on a voluntary- 
basis. Participants’ profiles were based on gender, age and experience to get a better understanding of the leadership role of the selected facilitator, their expectations, and successes of collaboration and challenges of working as a group.In depth individual interviews were conducted using a semi structured interview schedule as an instrument. The participants were asked questions the researcher perceived as important for facilitator group leadership.

\section{Data Analysis}

A qualitative data analysis of the responses to semi-structured interviews (Rourke and Anderson 2004; Wilson 2001) was done. Based on qualitative data analysis of semi-structured interviews, five leadership and facilitative factors were identified, namely: (a) individual accountability, (b) affective team support, (c) the presence of a positive group leader, (d) consensus building skills, and (e) clear instructions. An iterative process was used to code and categorise responses to identify themes from facilitators' responses and from literature. Codes were organised around the following categories: Individual accountability; The presence of a positive group leader; Affective team support; Consensus team building skills. The biographical information of all participants involved in the study is given in Table 1.

\section{RESULTS}

Leadership roles of FGLs for effective delivery of the DE programme focuses on the display of exemplary leadership skills outlined in group

Table 1: The biographical information of all participants involved in the study

\begin{tabular}{llcr}
\hline Participant & Gender & Age & $\begin{array}{c}\text { Facilitation } \\
\text { experience }\end{array}$ \\
\hline $\begin{array}{l}\text { Facilitator (Group } \\
\text { leader) 1 }\end{array}$ & Male & 60 & 9 years \\
$\begin{array}{l}\text { Facilitator (Group } \\
\text { leader) 2 }\end{array}$ & Male & 60 & 10 years \\
Facilitator 1 & Male & 58 & 8 years \\
Facilitator 2 & Male & 56 & 5 years \\
Facilitator 3 & Female & 48 & 6 years \\
Facilitator 4 & Female & 58 & 12 years \\
Facilitator 5 & Male & 49 & 5 years \\
Facilitator 6 & Male & 44 & 6 years \\
Facilitator 7 & Female & 52 & 8 years \\
Facilitator 8 & Female & 50 & 7 years \\
\hline
\end{tabular}

leadership roles. Selected group leaders are males and have been in this position for several years. The group leaders are not trained but have a booklet that reminds them of their roles and responsibilities. They are required to lead teams to achieve team goals and to deliver quality teaching and learning at Contact Sessions. Female participants interviewed in this study felt that qualifying facilitators were denied equality of opportunity and that the selection criteria was not transparent and fair since they had the same group leaders for years and other skilled facilitators were not approached. Both male and female facilitators and the group leader agree they are all experienced and competent in facilitation skills. Data below present discussions according to the aims of the study and the research questions. The gap identified in literature is lack of structure or process for the selection of facilitator group leaders for DE contact sessions.

\section{Theme 1: Individual Accountability}

Participants interviewed in this study gave mixed reactions about being approached for leading facilitators at DECs. Some were approached while others did not know how some facilitators came to be group leaders. The participants cited individual accountability as the main reason they were approached for leading facilitators at a distance education contact session. These were the responses from the FGLs:

I was approached because I have a good track record. I am hardworking, committed and passionate about facilitating to DE students (FGL1).

Another participant who felt he was a hard worker commented as follows:

I am hard working and always get positive comments from students' evaluations. I was approached telephonically to replace an incompetent group leader (FGL2).

There was also a participant who felt the selection of facilitator leaders was not fair because he was not approached nor has he ever heard of a selection process for FGLs. This is what she said:

I was never approached and I have never heard of facilitators going through a selection process to become group leaders. I just see people being called group leaders but do not know how it happens (Facilitator7). 
Theme 2: The Presence of a Positive Group Leader

Regarding facilitators preparation to address facilitator expectations for facilitator leadership, the facilitator mentioned the following:

We were invited to a training workshop where the unit manager gave power point presentations about what is expected of a FGL. He emphasised leadership and management skills which entailed being pro-active, approachable, organised, a good communicator who can manage time (FGL1).

Another facilitator stated that it was not a training as such, but a formal explanation of how they should make prior preparation, do administrative tasks like notifying facilitators of the travel and venue logistics. This facilitator commented as follows:

The Unit manager said he expected all of us to be knowledgeable about what should happen at distance education and that we should have leadership skills and be committed to creating a climate conducive to teaching and learning (FGL2).

All facilitators and the group leaders understood what should happen at the distance education contact session even though they had never been trained. This is what one facilitator said:

So far all group leaders are good leaders. There is team spirit and we are all involved in the preparation tasks at the contact session. We all travel to the venues and assist in putting up notices of the module venues and the times (Facilitator 8).

\section{Theme 3: Affective Team Support}

According to all facilitators the group leaders perform their roles well and display leadership and management skills. They are supportive and understand the different facilitators. The following responses were made:

I have always had a group leader who is committed and dedicated to his work. My group leader is empathetic, active and approachable. I like the fact that he is always organised and communicates everything to us (Facilitator1).

Another facilitator also indicated the positive and supportive character of the group leader as follows:

As soon as we get to the contact session, we are allowed to settle in and then come to a meeting. There the FGL outlines the tasks of all facilitators start helping with the given task and then we start working as a team. All facilitators are mature and responsible. They show administrative and leadership skills (Facilitator 2).

The group leaders were also confident and assertive of the fact that they do the best when coming to their roles as leaders. One of them commented:

As a FGL my role is clear because this was outlined to us at the group leader meeting. I have been a FGL for several years and we have a booklet that reminds us of our roles and responsibilities. I have good time management skills because I prepare in time (FGL1).

\section{Theme 4: Consensus Team Building Skills}

The facilitators stated that there were harmonious relationships among all team members because of the good leadership and management, expert facilitators, required resources which result in a cohesive team. One facilitator said:

We are a strong group because all of us are mature and work as a team. We are never reminded about our tasks because we enjoy the contact sessions (Facilitator 3).

There is great team spirit, friendliness and camaraderie. All facilitators are supportive and praise me for the good logistical arrangements (FGL 4).

On the contrary, one facilitator was not happy and said that the FGL did not allow them to use the hired cars when they needed to get food or medication. This however, indicated that the FGL did not trust them but needed them to help in tasks.

We are given good cars for transportation, however, the FGL owns the cars and do not want us to use them even if it is for important matters such as getting medication from the chemist. He would rather accompany me to get the medication. I think this is silly (Facilitator $6)$.

Another facilitator was not happy that the message about the travel logistics was communicated the day before they had to depart for the contact session. This is what the facilitator said:

I only received the message that we are leaving the next day in the afternoon when I came from work. The FGL said that he tried me sever- 
al times but I had no missed calls on my phone (Facilitator 5).

\section{Theme 5: Clear Instructions}

All participants indicated that they were provided with clear instructions though there was no policy. This is how one facilitator commented:

I am satisfied with the leadership, the leadership selection, leadership role and selected facilitators are the best group for the DE contact sessions. That is why the contact sessions are a success (Facilitator 1).

\section{Research Questions and Themes}

The research questions and the themes reflected in the following table are followed by a detailed explanation as indicated in Table 2.

Findings from the participant responses revealed that facilitator leaders had good interactions with facilitator groups. The cooperation between the FGL and the led facilitators is ascribed to the facilitators' experience as well as knowing what was expected of them, hence the recommendation that group leadership be rotated among facilitators. Findings further indicate that facilitators have excellent and skilled group leaders who maintain a healthy relationship with the facilitators with less impeding factors. Facilitators acquire some leadership skills from participating in the collaborative decision making they have with the group leader.

\section{DISCUSSION}

FGLs are collaborative leaders who cannot exist without a group. To succeed they should have strong support from their groups. A FGL is a temporary task leader who takes care of tasks at the Distance Education centre. FGLs engage their groups to get the group to work as one. The FGL is also a facilitator who understands the group and builds a relationship that enables everyone to work collaboratively. Since facilitative skills are needed to become a group leader, anyone moving into a leadership role should be a facilitator first. In leading, the group or team, both the FGLs and facilitators should have the ability to communicate so as to manage conflict and make the group successful. Both are successful only when the team is successful. FGLs discover facilitative factors through collaboration and impeding factors such as late communication of DE contact session information, and technology are problems.

\section{CONCLUSION}

Running a support group for students through FGL and facilitators is not as easy as it seems. It is very useful to understand how people behave in groups and how helpful they can be to one another in a group setting. Leading an effective group begins with a commitment to three basic assumptions: each member can make a contribution, each member is the ultimate authority on their needs and what will work for them, and communication must be open and honest to promote a positive group experience. FGLs should ensure that there is a healthy relationship and group cohesion among facilitators at DE Contact Sessions (CS) for better facilitator delivery of modules..

\section{RECOMMENDATIONS}

Recommendations were that payment be the same for all facilitators and the FGLs because all

Table 2: Research questions and themes

\begin{tabular}{lll}
\hline Research question & Themes \\
\hline $\begin{array}{l}\text { Were you ever approached to be a group leader and } \\
\text { are you one? If yes/no what do you think are the } \\
\text { reasons? Explain in full. }\end{array}$ & Individual accountability \\
$\begin{array}{l}\text { What facilitator preparations were provided to } \\
\text { address facilitator expectations for group } \\
\text { leadership? }\end{array}$ & The presence of a positive group leader \\
$\begin{array}{l}\text { What were the experiences of leading facilitators } \\
\text { at a DECS? }\end{array}$ & Affective team support \\
$\begin{array}{l}\text { How do group leaders ensure teamwork at contact } \\
\text { Sessions? }\end{array}$ & Consensus team building skills \\
5. What more can you recommend for group leadership? & Clear instructions \\
\hline
\end{tabular}


had individual accountability and worked as a team, instead of the FGL alone getting paid extra for group leadership. Individual accountability is an essential element for facilitator group leadership and a competency necessary for delivery of an effective DE program. Facilitators feel that group leadership should be on a rotational basis since excellent leadership resulted from experience, commitment, teamwork and support of all facilitators. Since the group leader's duties are minimised by the cordial relationship and participative decision-making, the FGL is left with fewer tasks to perform and there is a minimal need for micromanagement by the group leader. It is further recommended that FGL training program satisfy the changing role of the FGL. This should include facilitator communication skills and interaction with facilitators; constructive and timely feedback to facilitators; facilitators guidance in methods of effective teamwork to improve strengths of collaborative work with others to produce effective DE delivery. The findings of this study may inform institutions using group leader components at DE contact sessions of strategies to use when appointing facilitators for group leadership at DE contact sessions. The findings in the paper have the potential to create an awareness of this type of leadership in comparison to other types of leadership in education.

\section{REFERENCES}

Abrami PC, Bernard RM, Bures EM, Borokhovski E, Tamim RM 2011. Interaction in distance education and online learning: Using evidence and theory to improve practice. Comput High Educ, 23: 82-103.

An H, Kim S, Kim B 2008. Teacher perspectives on online collaborative learning: Factors perceived as facilitating and impeding successful online group work. Contemporary Issues in Technology and Teacher Education, 8(1): 65-83.

Barkley EF 2010. Student Engagement Techniques: A Handbook for College Faculty. San Francisco: Jossey-Bass.

Bush T 2008. Leadership and Management Development in Education. London: Sage Publication.

Bush T 2010. The Importance of Leadership and Management for Education: Theories of Educational Leadership and Management. London: Sage Publications.

Copeland S 2010. The 40 ${ }^{\text {th }}$ Annual Conference of the International Society for Exploring Teaching and Learning (ISETL). Nashville, TN: Clayton State University.

Department of Higher Education and Training 2014. Policy for the Provision of Distance Education in South African Universities in the Context of an In- tegrated Post School System. Government Gazette, No. 37811 of 7 July 2014. Pretoria: Department of Education.

Glenn L 2009. Structure and soul. The Academy Leadership Journal, 15(1): 12-20.

Mampane ST 2009. How Public School Governing Bodies Understand and Implement Changes in Government Legislation with Respect to the Selection and Appointment of Teachers. South Africa: University of Pretoria.

Mampane ST, Ogina TA 2012. Facilitator training for distance education contact sessions. Progressio, 34(1): 144-155.

Mampane ST 2015. Procedures and processes followed in the appointment of principals for school leadership and management. Journal of Social Sciences, 42(3): 239-245.

Marmor A 2005. Authority, equality and democracy. The School of Law and the School of Philosophy, 18(3): 315- 345

Matsilitsa MG 2007. Handbook of Distance Education. $2^{\text {nd }}$ Edition. London: Routledge.

Moen A, Anders I, Mørch AI, Paavola S (Eds.) 2012. Collaborative Knowledge Creation Practices, Tools, Concepts. Rotterdam: Sense Publishers.

Muhirwa J 2009. Teaching and learning against all odds: A video-based study of learner-to-instructor interaction in international distance education. International Review of Research in Open and Distance Learning, 10(4): 201-208.

Napier NP, Johnson RD 2007. Technical projects: Understanding teamwork satisfaction in an introductory IS course. Journal of Information Systems Education, 18(1): 39-46.

Northouse PG 2010. Leadership: Theory and Practice. $5^{\text {th }}$ Edition. Thousand Oaks, CA: Sage Publications.

Ogina TA, Mampane ST 2013. Experiences of tutorial sessions as learning support for distance education students. Progressio, 35(1): $104-118$.

Roberts J, Roach J 2006. Leadership Styles and Practices in Effective Schools. Johannesburg: Matthew Goniwe School of Leadership and Management.

Saunders P 2011. The Rise of the Equalities Industry. London: Civitas: Institute for the Study of Civil Society.

Swartz RJ 2008. Energizing learning. Educational Leadership, 65(5): 26-31.

Taylor JC 2001. $5^{\text {th }}$ Generation Distance Education. DETYA's Higher Education Series, Report No.40, June, ISBN $064277210 X$. From <http://www. dest.gov.au/sectors/higher_education/publications_ resources/> (Retrieved on 15 October 2014).

University of Pretoria 2012. Unit for Distance Education: Responsibilities of Group Leaders. Guide for Mentors. Pretoria: University of Pretoria.

Van Emmerik H, Jawahar I, Schreurs B, De Cuyper N 2011. Social capital, team efficacy and team potency: the mediating role of team learning behaviors. Career Development International, 16(1): 82-99.

Vos M, Van Der Zee K 2011. Prosocial behavior in diverse workgroups: How relational identity orientation shapes cooperation and helping. Group Processes and Intergroup Relations, 14(3): 363-379.

Yeager KL, Nafukho FM 2012. Developing diverse teams to improve performance in the organizational setting. European Journal of Training and Development, 36(4): 388-408. 